\title{
Personality predictors of creative achievement and lawbreaking behavior
}

\author{
Izabela Lebuda ${ }^{1}$ (D) Maciej Karwowski ${ }^{1}$ - Adrianne John R. Galang ${ }^{2,3}$ • Grzegorz Szumski ${ }^{4}$. \\ Anna Firkowska-Mankiewicz ${ }^{5}$
}

Published online: 4 June 2019

(C) The Author(s) 2019

\begin{abstract}
This article investigates how Big Five personality traits are related to creative achievements and lawbreaking behavior in a large sample $(N=1669)$ of Polish adults. Structural equation modelling with personality modelled as a bi-factor structure demonstrated a weak, yet significant link $(r=.21)$ between latent factors of creative achievements and lawbreaking behavior. A general factor of personality was unrelated to creative achievement, but negatively linked to lawbreaking behavior. Lawbreaking behavior was also negatively predicted by conscientiousness and agreeableness, while only openness positively predicted creative achievement. A person-centered analysis illustrated three distinct personality profiles: resilient, undercontrolled, and overcontrolled that differed in both lawbreaking behavior and creative achievements.
\end{abstract}

Keywords Creative achievement $\cdot$ Lawbreaking behavior $\cdot$ Personality $\cdot$ Bi-factor model $\cdot$ Latent profile analysis

While being creative is often equated with being morally good and psychologically healthy (e.g., Csikszentmihalyi et al. 2017; Kharkhurin 2014; Runco and Nemiro 2003), it seems to also have a morally disconcerting side (Cropley and Cropley 2010, 2013; Cropley et al. 2008; Cropley et al. 2010; Gamman and Raein 2010). Indeed, the association between creativity and the tendency towards socially undesirable behaviors was repeatedly observed (e.g., Feist 1999; Götz and Götz 1979; Hall and MacKinnon 1969). This link was previously discovered in a now classic study of architects, with the more eminent respondents scoring higher on aggression and emotional instability, lower on tolerance and with being more likely to lie and to control others (Hall and MacKinnon 1969) compared to the less eminent architects. Similar results were obtained in a study of scientists, showing

Izabela Lebuda

izalebuda@gmail.com

1 Institute of Psychology, University of Wroclaw, ul. J. W. Dawida 1, 50-527 Wroclaw, Poland

2 Masaryk University, Brno, Czech Republic

3 Nanyang Technological University, Singapore, Singapore

4 Faculty of Education, Warsaw University, Warsaw, Poland

5 The Maria Grzegorzewska University, Warsaw, Poland that those who were highly achieving and productive displayed higher hostility and a more arrogant style of working than their less creative peers (Feist 1999). Such links were also observed among artists, who scored higher in psychoticism than did representatives of other professions (Götz and Götz 1979).

One could suppose that the association of undesirable behaviors and creative accomplishments of successful artists or scientists is merely an effect of higher status or power that stems from gaining recognition in a domain (see e.g., Piff et al. 2012). Yet, such relationships have also been observed between mini- and little-c creativity (Kaufman and Beghetto 2009), and such traits as moral flexibility, dishonesty and deception (Beaussart et al. 2013; Gino and Ariely 2012; Gino and Wiltermuth 2014; Kapoor and Khan 2017; Silvia et al. 2011; Walczyk et al. 2008), narcissism, psychopathy, and Machiavellianism (Jonason et al. 2017; Jonason et al. 2015; McKay et al. 2017), as well as difficulty in recognizing one's own and others' emotions (Zenasni and Lubart 2009), emotional disinhibition and tendency to risk-taking (Galang et al. 2016), psychoticism (Eysenck 1993), aggressive outbursts, lawbreaking and unethical behavior (Johnson 1983; Mai et al. 2015).

One line of research in particular draws attention to the conceptual links between creativity (measured by objective convergent and divergent tests and problem solving tasks see Batey 2012) and rule-breaking (Gino and Wiltermuth 
2014; Mai et al. 2015), given that a similar departure from expectations is inherent in both phenomena. Gino and Wiltermuth (2014) identify at least one possible social cognitive mechanism: feeling less constrained by rules. The authors demonstrated that after being given an opportunity to cheat, the more unconstrained individuals felt that their score on tests of creativity were better. On a more interpersonal note, individuals with more conflict-related cognitions displayed increased originality and flexibility when the situation was competitive; the originality decreased within a cooperative situation (De Dreu and Nijstad 2008).

At the very least, such a result validates the expectation that creativity and unethical behavior are conceptually related. It also makes more plausible that the link between lawbreaking and creativity is more than just an incidental result of eminence and changes in life circumstances.

\section{Personality, Law-Breaking and Creativity}

In parallel to the social cognitive account, complementary theorizing from a personological perspective posits a more pervasive syndrome rather than a merely contextual effect. The synthesis was articulated by Eysenck (e.g., Eysenck 1993, 1994, Eysenck 1995), who proposed that both creativity and antisocial behavior may develop due to lower than normal arousal in the central nervous system; these two contrasting behaviors take shape through attempts to find an optimal level of arousal through risky and impulsive behavior (see Matthews and Gilliland 1999) - tendencies captured in trait psychoticism (P). This association has been observed for both creativity (Martindale 1999) and deviant behavior (e.g., Lynam and Miller 2004). What is more, the meta-analytic review of 32 studies, indicates that the relationship between creativity and psychoticism is robust, yet moderated by the way how psychoticism is operationalized (Acar and Runco 2012).

Although Eysenck was more focused on the schizotypal side of P, Galang (2010) took up this line of reasoning in an attempt to explain the consistent association of disagreeable traits with creativity. The result is the "prosocial psychopath" hypothesis, which identifies cognitive and affective disinhibition as important drivers of the features that are expected to be common to both creative personalities and psychopaths (Galang et al. 2016). Dopaminergic mechanisms, especially in mesolimbic and prefrontal brain regions, are thought to partly explain why these features co-occur with creativity (Galang 2010).

Both the personological (Eysenck 1995; Galang et al. 2016) and social cognitive hypotheses (De Dreu and Nijstad 2008; Gino and Wiltermuth 2014) would lead to expect that if disagreeableness and dishonesty were related to creativity, behaviors related to these traits should be expressed by creative persons even outside of the context of creative activity. Cognitive and affective disinhibition should predispose some creative people to entertain the unlikely, risky, non-normative, and occasionally illegal courses of action (Galang et al. 2016), while at the same time feeling flexible and unrestrained enough to enable them to justify the actions once selected or enacted (Gino and Ariely 2012). That is not to say that lawbreakers and creatives would be the same set of individuals, but that they could intersect. Although both groups are high in $\mathrm{P}$, it should be possible to distinguish between them from a Big Five perspective, given that there is evidence that Eysenck's $\mathrm{P}$ is a composite of agreeableness, conscientiousness, and, to a lesser extent, openness (Saggino 2000). Consistent with the literature, we would expect highly creative persons to score high on openness to experience and low on agreeableness (e.g., Silvia et al. 2012; Feist 1999; Karwowski and Lebuda 2016; Karwowski et al. 2013), while those who are more cardinally described as lawbreakers would be primarily characterized by low agreeableness and conscientiousness (Decuyper et al. 2009; Miller and Lynam 2001; Lee and Dow 2011).

\section{The Present Study}

This study has two main goals. First, we explore the links between creative achievements and lawbreaking behavior in a large sample of adults. Second, we test the role played by Big Five personality traits as predictors of both creative achievements and lawbreaking behavior. Analytically, we integrate variable- and person-centered approaches to untangle the abovementioned links.

\section{Method}

\section{Participants and Procedure}

A total of 1669 individuals (1057 women, 63\%), inhabitants of the city of Warsaw (Poland), participated in this study. All participants were born in 1963. All participants took part in the follow-up of a longitudinal investigation, the Warsaw Study (Firkowska et al. 1978; Firkowska-Mankiewicz 2002, 2011, see also Karwowski et al. 2017). They were contacted by an external research agency and interviews took place in their homes.

\section{Measures}

Lawbreaking Behavior A latent factor describing participants' behaviors related to breaking norms or law was modelled on four observed indicators that determine how many times in the last 10 years $(1=$ never; $2=$ very rarely: once or twice; $3=$ 
rarely: three to five times; $4=$ often/a few times: between five and 10 times; $5=$ very often/many times: more than 10 times) the participant (1) took drugs / tried drugs, (2) was accused of doing something punishable by imprisonment; (3) was charged in a civil case; (4) or caused a traffic accident. Internal consistency of the scale based on matrices of polychoric correlations was high: $\alpha=.81$.

Creative Achievement To measure participants' creative achievement, we used the Creative Achievement Questionnaire (CAQ; Carson et al. 2005). CAQ measures lifetime creative achievements in 10 domains: (a) visual arts; (b) music; (c) dance; (d) architectural design; (e) creative writing; (f) humor; (g) inventions; (h) scientific discovery; (i) theater and film; and (j) culinary arts.

In each domain, a sub-scale contains eight ranked questions weighted with a score from 0 to 7 ( 0 means no achievement and 7 means achievements recognized in the domain at national level). Scores on all domains summed to the total CAQ score for each person (Carson et al. 2005).

Reported achievements on the scale are to some degree objective and observable by others, mainly because they are expected to be public (e.g. awards, publicized recognition). Based on matrices of polychoric correlations, CAQ's reliability was acceptable $(\alpha=.76)$.

Personality We used a 50-item scale composed of items from the International Personality Item Pool (Goldberg 1999; Goldberg et al. 2006; Polish adaptation Strus et al. 2014). It includes ten items for each Big Five personality factor, rated with the use of a 5-point scale ( $1=$ completely inaccurately describes me, $5=$ completely accurately describes me). Cronbach's $\alpha$ : extraversion $(\mathrm{E})=.82$; agreeableness $(\mathrm{A})=.86$; conscientiousness $(\mathrm{C})=.84$; neuroticism $(\mathrm{N})=.83$; and openness to experience $(\mathrm{O})=.70$.

\section{Results}

Before creating our main models, we started with a series of confirmatory factor analyses (CFA) to examine the structure and fit of personality, creative achievement and lawbreaking behavior constructs. Since our personality instrument is based on the Big Five theorizing, we assumed that a structure with five latent factors would be characterized by a satisfactory fit. The initial CFA model with five correlated factors of personality was characterized by a relatively poor fit, as evidenced by a comparative fit index $(C F I)$ of .80 , and a Tucker-Lewis Index (TLI) of .79, although root mean square error of approximation (RMSEA) of .048 (90\% confidence intervals: $.047-.050)$ and standardized root mean square residual $(S R M R)$ of .057 were generally acceptable.
As an alternative, we examined a bi-factor solution, where we assumed that, alongside five personality factors, there was a further single latent factor accounting for variance in the items, and that this was also a firstorder latent factor (i.e. same level as the five factors). Given that it has been argued that the reproducible "general factor" derived from personality inventories (Musek 2007; Just 2011) actually represents a social desirability factor (Bäckström et al. 2009), accounting for it when modeling relationships between self-report measures might deliver two benefits: it can improve the internal consistency of the self-report items while allowing social desirability effects to be partialled out of the correlations of interest.

The bi-factor model with five traits alongside a single general factor was characterized by a better fit, although it still fell slightly short of recommended criteria (Hu and Bentler 1999): $C F I=.85, T L I=.84$, RMSEA $=.043,90 \%$ CI: $.042-.044$, $S R M R=.048$. We decided to proceed with this model in our further analyses. Almost all items significantly loaded on the Big Five factors they were identified with, but also a clear general factor emerged (see Appendix Table 1). The model fit for a latent lawbreaking behavior (LB) factor was acceptable: $C F I=.95$, TLI $=.86, R M S E A=.026,90 \% C I: .00-.06$, $S R M R=.047$, which was also the case for the model for creative achievement: $C F I=.947, \mathrm{TLI}=.932, R M S E A=.040$, 90\% CI: .034-.046, SRMR $=.051 .^{1}$ Models for personality were tested using maximum likelihood estimator with robust standard errors (MLR), while models for creative achievement and antisocial behavior, due to severe skewness of responses and their ordinal scale, were created using weighted least squares mean corrected estimator (WLSM; Muthén 1993) in R (package lavaan, see Rosseel 2012).

Our final model regressed the latent creative achievement variable and latent lawbreaking behavior on five personality traits, as well as on the single factor using WLSM estimator. This model yielded a good fit: $C F I=.960, T L I=.957$; $R M S E A=.042,90 \%$ CI: $.041{ }^{2} .043$, SRMR $=.047$. Creative achievement and lawbreaking behavior shared a small albeit significant portion of common variance $(r=.21, p=.003)$, yet their predictors differed. While lawbreaking was negatively linked to the general factor and to conscientiousness and agreeableness, the CAQ factor was associated only with openness (see Fig. 1).

To test for potentially more nuanced patterns that might not be sufficiently well captured by our rather

\footnotetext{
${ }^{1}$ We emphasize that in case of these models $C F I$ and $T L I$ (and more generally, incremental fit indices) may not be very informative, because the baseline (null) model's RMSEA was lower than .158 (a cut-off recommended by Kenny et al. 2015): in the case of LB null-model $R M S E A=.069$, in the case of CAQ RMSEA = .152. Therefore, our estimates of RMSEA serve as indices of model fit. We thank the anonymous reviewer for this suggestion.

${ }^{2}$ RMSEA for a null model was estimated at .204, so above the cut-off recommended by Kenny et al. (2015).
} 
Fig. 1 A bi-factor model of the higher-order effects of the general factor of personality and the lower-order effects of personality traits on creative achievements and lawbreaking behavior. Note. $\# p<.10, * p<.05 ; * * p<.01$

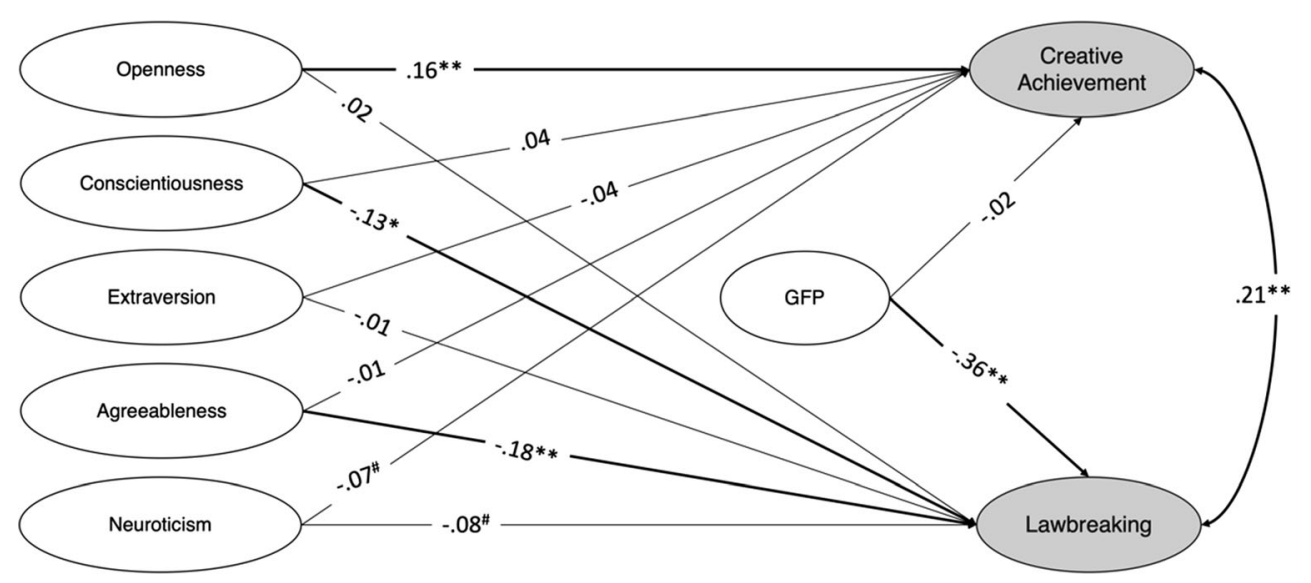

general structural equation model, ${ }^{3}$ we decided to proceed with a person-centered approach. To this end, we conducted a latent profiles analysis using personality items as criteria for classification in MPlus 8 (Muthen \& Muthen, 1998-2017). Based on the existing literature (Asendorpf and van Aken 1999; Robins et al. 1996), there were reasons to expect a three-profiles solution, namely resilient, undercontrolled, and overcontrolled profiles. Resilient people are characterized by low neuroticism, high extraversion and conscientiousness, undercontrolled type holds low agreeableness and conscientiousness, while overcontrolled people have low extraversion and high neuroticism. Indeed, a threeprofile model was characterized by a good fit, with entropy $=.93$. Importantly Lo-Mendell-Rubin adjusted Likelihood Ratio Test (LRT; Lo et al. 2001) indicated the best fit with a three-profiles model, as compared to the 2-profiles (LRT test $=256,145 ; p<.001$ ), and four-

\footnotetext{
${ }^{3}$ An anonymous reviewer has also suggested that given our focus on previous works that posit the role of $\mathrm{P}$ or dark triad for creativity, our study would benefit from re-constructing some dark triad factors from our Big Five measure. While we agree and appreciate this suggestion, it wasn't fully possible in our case, mainly because our instrument contained only a small fraction of items that could be theoretically linked to dark triad. Still, however, after an analysis of items' meaning, for exploratory purposes we selected 5 items ("I feel little concern for others," "I insult people," "I am not interested in other people's problems," "I am not really interested in others," "I get irritated easily"). This resulted in a highly reliable scale $(\alpha=.81)$, that was strongly negatively related to agreeableness $(r=-.54, p<.001)$ and positively with neuroticism $(r=.12, \mathrm{p}<.001)$ and openness $(r=.05, p=.04)$, while it remained unrelated with conscientiousness $(r=.01, p=.69)$ and extraversion $(r=.02, p=.33)$. Conceptually these items were closest to psychopathy or partially Machiavellianism rather than to narcissism. This newly created scale was positively related to $\mathrm{LB}(r=.25, p<.001)$ and negatively to the overall score in creative achievement (log-transformed): $r=-.08, p=.001$. Interestingly, when we examined links between this exploratory scale and specific CAQ domains, we observed negative correlations with achievement in the domains of music $(r=-.06, p=.02)$, dance $(r=-.09, p<.001)$, and culinary arts $(r=-.10, p<.001)$, while there were positive links with creative writing $(r=.13, p<.001)$ and inventions $(r=.08, p=.001)$.
}

profiles model failed to converge. The profiles of the three groups are presented on Fig. 2.

Given the patterns presented on Fig. 2, the first profile ( $n=$ $347 ; 21 \%$ ) was a resilient one (low neuroticism, stable and relatively high extraversion, openness and conscientiousness), the second profile $(n=494 ; 30 \%)$ was overcontrolled (high agreeableness and conscientiousness associated with relatively high neuroticism and low extraversion and openness), while the last, third profile $(n=828 ; 49 \%)$ : undercontrolled and was characterized by high neuroticism and relatively low intensity of the remaining big five traits.

We compared the intensity of LB and creative achievements (in general and across different domains) between the different profiles. More specifically, we processed it in two-steps, both based on MANOVA. The first MANOVA compared results in our two main variables of interests - LB and CAQ across profiles. Differences were statistically significant in the case of CAQ (log transformed), $F(2,1668)=11.60, p<.001$, $\eta_{\mathrm{p}}^{2}=.014$ and LB, $F(2,1668)=46.93, p<.001$, $\eta_{\mathrm{p}}{ }^{2}=.053$ (see Fig. 3). Pairwise comparisons with Sidak correction did demonstrate that in the case of CAQ undercontrolled profile reported lower creative achievement than both resilient $(p<.001)$ and overcontrolled $(p=.02)$, while the difference between resilient and overcontrolled did not reach statistical significance $(p=.12)$. In the case of LB, all groups differed from each other, with the resilient reporting the lowest level of LB - significantly lower than the overcontrolled $(p=.009)$ and the undercontrolled $(p<.001)$, while the overcontrolled reported lower LB than the undercontrolled $(p<.001)$.

To examine potential domain-specific effects, we proceeded with the next MANOVA, this time with all ten domains of CAQ as dependent variables and personality profile as between subject factor (see Fig. 4). We observed statistically significant differences in five out of ten domains. More specifically, the profiles differed 
Fig. 2 Personality of three groups obtained in LPA

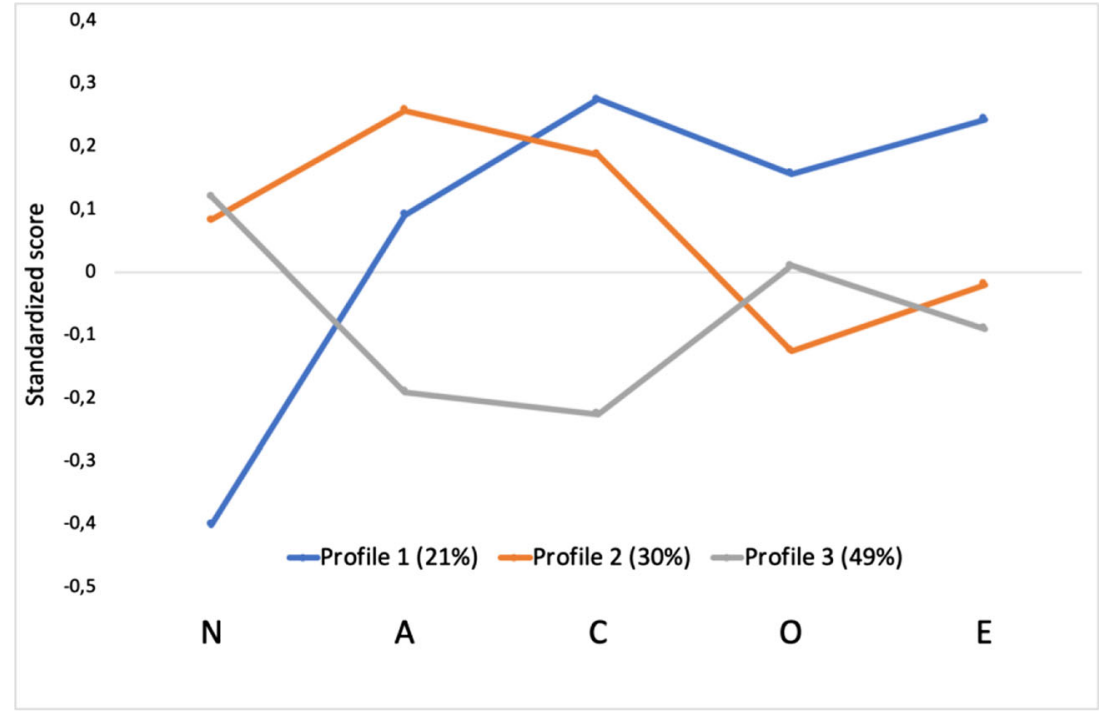

in terms of creative achievement in dance, $F(2,1668)=$ $11.35, p<.001, \eta_{\mathrm{p}}{ }^{2}=.013$; creative writing, $F(2$, $1668)=13.30, p<.001, \eta_{\mathrm{p}}{ }^{2}=.016$; humor, $F(2$, $1668)=4.74, p=.009, \eta_{\mathrm{p}}{ }^{2}=.01$; inventions, $F(2$, $1668)=7.59, p=.001, \eta_{\mathrm{p}}{ }^{2}=.01 ;$ and culinary arts, $F(2$, $1668)=7.34, p=.001, \eta_{\mathrm{p}}^{2}=.01$. In the remaining cases, there were no statistically significant differences between profiles (all $F \mathrm{~s}<2$ ).

Interestingly, a look at Fig. 4 illustrates that previously reported differences in creative achievement across profiles are qualified by the domain of creativity. Although we emphasize that this finding was not a priori hypothesized, we believe it could contribute to the discussion of domain-specificity of creativity and its personality predictors (e.g., Feist 1999). In the case of dance the resilient type reported higher creative achievement than the undercontrolled type $(p<.001$,
Cohen's $d=0.30)$, while did not differ from the overcontrolled type ( $p=.43$, Cohen's $d=0.043)$, and the overcontrolled type reported higher achievement than the undercontrolled type $(p=.003$, Cohen's $d=$ $0.21)$. This pattern was replicated in culinary arts: the resilient type reported significantly higher achievement than the undercontrolled ( $p=.002$, Cohen's $d=0.22$ ) but not the overcontrolled type $(p=.74$, Cohen's $d=0.05)$ and the overcontrolled type declared higher achievement than the undercontrolled type $(p=.012$, Cohen's $d=$ $0.16)$. In the case of creative writing the undercontrolled reported higher achievement than the resilient $(p<.001$, Cohen's $d=0.29)$ and the overcontrolled $(p=.001$, Cohen's $d=0.20$ ), but no differences between the resilient and the overcontrolled types were noted $(p=.35$, Cohen's $d=0.11$ ). The same pattern was found in the case of invention, with a significant difference between
Fig. 3 Creative Achievement and LB across personality profiles (Note. Due to different scales, both variables were standardized to facilitate comparisons. Error bars denote $95 \%$ confidence intervals around the mean)

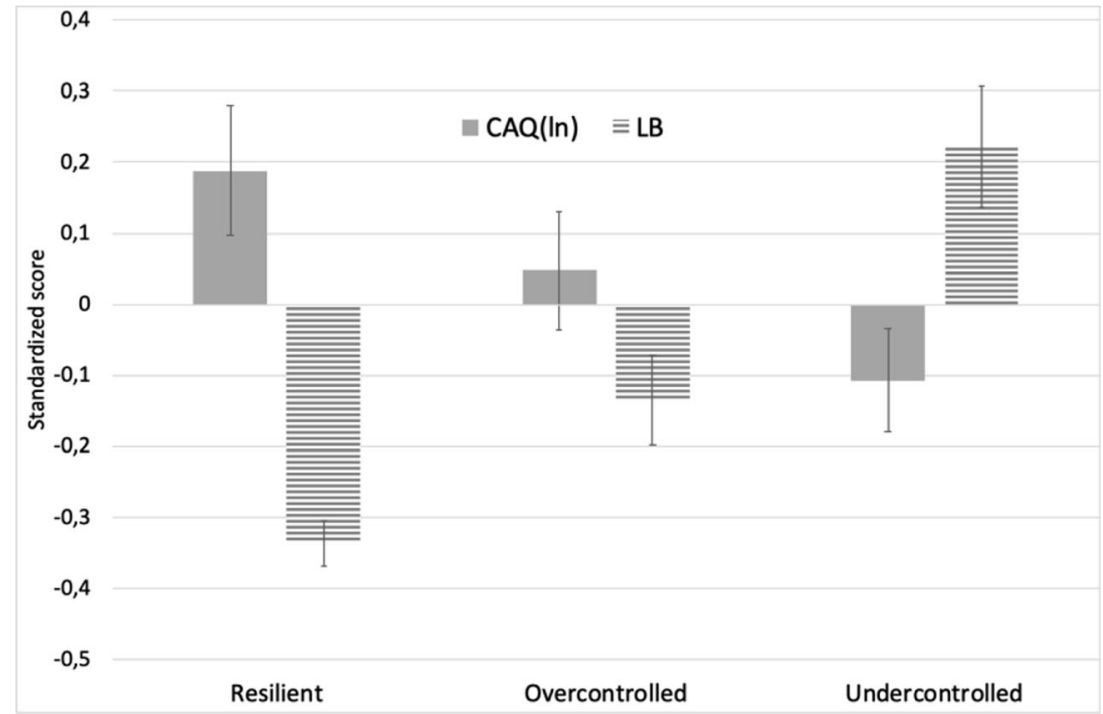


the undercontrolled and the resilient $(p<.001$, Cohen's $d=0.23$ ) and the undercontrolled and the overcontrolled ( $p=.041$, Cohen's $d=0.13$ ) and lack of differences between the overcontrolled and resilient $(p=.34$, Cohen's $d=0.11)$. In the case of humor, the resilient scored significantly higher than the over- $(p=.018$, Cohen's $d=$ $0.19)$ and undercontrolled groups $(p=.012$, Cohen's $d=$ 0.18 ), while the latter two did not differ one from the other ( $p=.99$, Cohen's $d=0.01$ ). All comparisons were made with a Tukey's correction for multiple tests. We emphasize the tiny effect size of these differences, which - together with an exploratory status of this analysis - calls for replication of this pattern in future studies.

\section{Discussion}

Our findings show a modest but significant association between creative achievement and lawbreaking behaviors. This further supports previous hypotheses about shared psychological features between these dispositional tendencies (Eysenck 1995; Galang 2010). However, this interpretation will need to be framed in terms of the patterns yielded by the larger model.

Although it was posited in an exploratory manner, the bi-factor model we applied is nonetheless theoretically justifiable and seems, for the current data, empirically sound. Given that the latent single factor seemed to be strongly and negatively associated with selfreported lawbreaking, it would seem to motivate an interpretation that this general factor is a social desirability variable (Bäckström et al. 2009). This pattern fits with previous observations that Eysenck's P, which is a dimension associated with social deviance and antisocial tendencies, correlates negatively with scores on lie scales (Eysenck \& Eysenck, 1975, as cited in Howarth 1986). Lawbreaking was also, as expected, associated with low agreeableness (see Eysenck 1995) and low conscientiousness, in line with predicted links between self-control deficits and antisocial behavior (see also Dacey and Lennon 1998; Kipper et al. 2010).

CAQ scores were predicted by openness, which is a fairly standard finding (Kaufman et al. 2015; Feist 1999; Silvia et al. 2011). On the other hand, the expected negative association between creative achievement and agreeableness was not observed. This might indicate that the variance in agreeableness that is usually associated with creativity has already been accounted for by the lawbreaking factor. Whatever underlies the phenotypic tendency towards lawbreaking could explain the consistent observation of low agreeableness in creative persons. This might be $\mathrm{P}$ (Eysenck 1995) or, if we cautiously interpret the trend for creativity to be associated with a resilient profile, it might be the fearless dominance or boldness factor in psychopathy (Galang 2010; Galang et al. 2016). Alternatively, this might have been due to the inclusion of the general factor in the model, although we also note that this factor was not associated with creative achievement in this dataset.

The three type of personalities (Asendorpf and van Aken 1999; Robins et al. 1996), identified in the latent
Fig. 4 Creative Achievement across Personality Profiles (Note. error bars denote $95 \%$ confidence intervals around the mean)

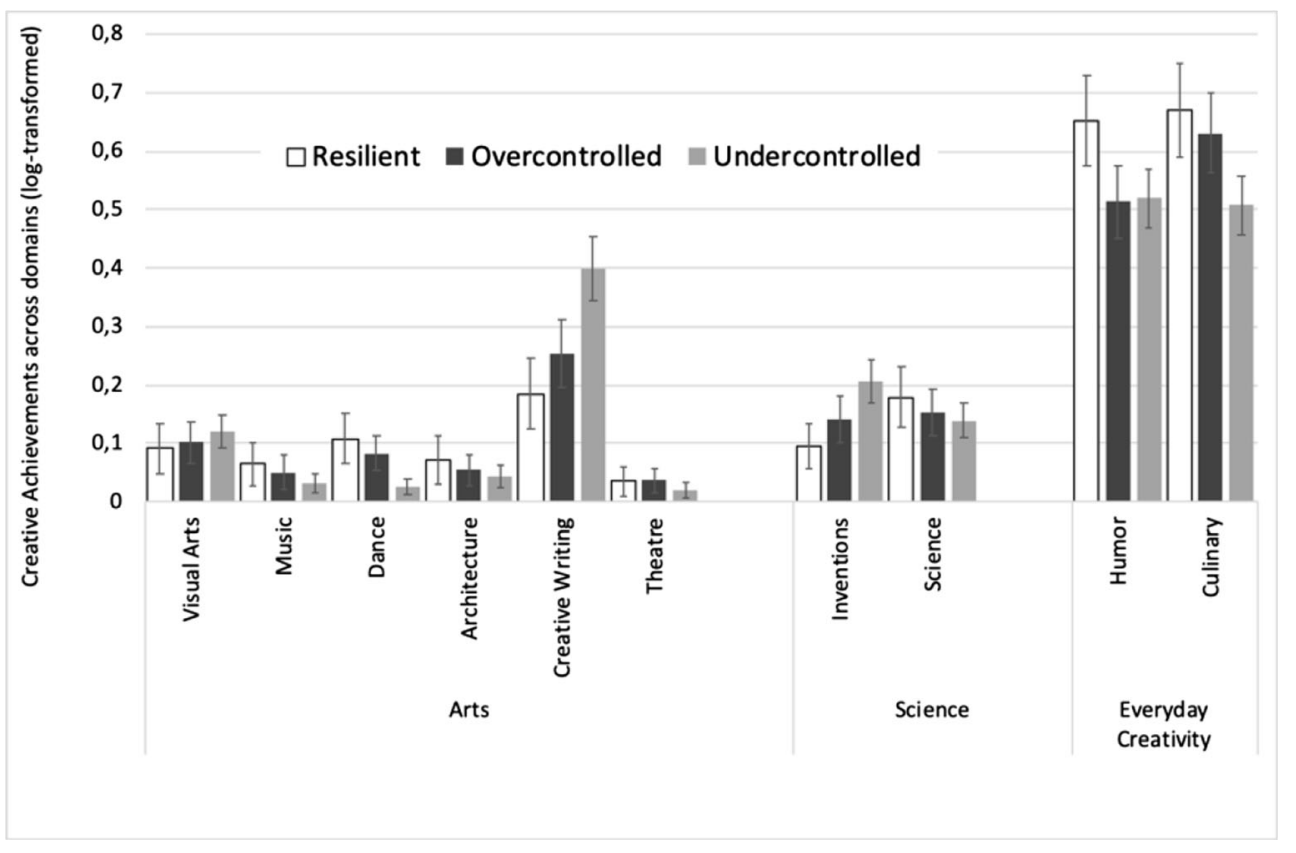


profile analysis with personality items as criteria for classification differed in case of lawbreaking and creative achievements in general and across domains. The undercontrolled reported lower creative achievements and were higher in lawbreaking than the resilient and overcontrolled types. The resilient type had significantly lower level of lawbreaking behaviors than the overcontrolled. The undercontrolled reported higher achievement in creative writing and invention than the resilient and the overcontrolled, while the resilient type reported higher achievement in dance, culinary art, and humor. These patterns are in line with previous findings that showed that undercontrolled people are more impulsive and disobedient, with higher tendency to delinquency then two other types (e.g. Akse et al. 2007; Robins et al. 1996; Weir and Gjerde 2002).

Although our data seems to support the literature linking creativity with lawbreaking behavior, there have been recent, well-argued critiques levelled against the related claims. Most of these focus on moral reasoning and demonstrate that no necessary relationship exists between creativity and dishonest or unethical behavior when examining decision-making and justifications (Shen et al. 2017; Niepel et al. 2015). While these results might pose a direct challenge for social cognitive accounts, this is less of a concern for personological theories that do not posit any such direct causal mechanisms. Both Eysenck (1995) and Galang (2010) believed that creativity and disagreeable behavior are not causally connected but are products of a common underlying personality process. The fact that trait psychopathy does not seem to be strongly related to any particular deficit in moral reasoning (Marshall et al. 2017; Marshall et al. 2018) is perfectly consistent with the claim that creative individuals display good moral judgment as well as with the saying that in spite of their capacity for moral reasoning, creative people are prone to engage in morally dubious behavior and lawbreaking. In addition, since our data concerns creative achievement, some of these critiques might not be directly relevant, since most of the contrary evidence and arguments seems to focus either on creativity tasks (e.g., Liu et al. 2014), "little-c" creativity (Niepel et al. 2015), or with anecdotal examples (Shen et al. 2017).

\section{Limitations and Future Directions}

The results of this study should be read in light of some methodological limitations. Although the data is comprised of a large sample of adults, all participants were of the same age, so our findings cannot be easily generalized if we accept that cohort differences may play a role here. It should also be emphasized that we jointly modelled two kinds of uncommon events: creative achievement and lawbreaking. As both these variables had over-dispersed Poisson distributions (see also Silvia et al. 2009) with excessive zeros and high scorers being very rare in the population, specific statistical methods were necessary to obtain unbiased estimates. We opted to model our variables as count measures rather than continuous scales, but further studies on how to properly treat data from these kinds of special populations - both highly creative or highly lawbreaking - should bring new insights and allow for even better understanding of the links between creativity and such socially undesirable tendencies. Finally, the study's reliance on self-report measurements, even when assessing ostensibly public achievements, may make it vulnerable to the usual response tendencies. This might have been partly ameliorated by the inclusion of the general latent factor, if indeed we are warranted in interpreting it as a putative social desirability factor. Yet even if that were the case, it would still be desirable to perform future studies using more objective measures of lawbreaking behavior and the underlying systems that it possibly shares with creativity. In the future, it is worth to replicate the presented research beyond the sample from Poland and recruit to the sample instances of lawbreaking that might be more frequent (e.g., prisoners).

\section{Conclusion}

In a large sample of middle-aged adults, we observed hypothesized relationships between personality traits on the one hand and two socially significant behaviors, namely lawbreaking and creativity, on the other. A less commonplace but not entirely surprising result, given previous theorizing, was the association between creative achievement and lawbreaking. We believe that this adds to an already substantial body of literature supporting the relationship between socially undesirable tendencies and creativity, but also rules out other previously observed predictors (e.g., agreeableness).

Acknowledgements This study was possible thanks to the funding obtained from National Science Centre, Poland (UMO2012/07/B/HS6/ 01438) for the last author.

\section{Compliance with Ethical Standards}

Conflict of Interest None.

Ethical Approval This study was carried out in accordance with the recommendations of The Maria Grzegorzewska University with written informed consent from all participants. The protocol was approved by the The Maria Grzegorzewska University Institutional Review Board (decision number 128-2016/2017). 


\section{Appendix}

Table 1 Factor loadings of IPIP-50 items on the general factor of personality and big five traits

\begin{tabular}{|c|c|c|c|c|c|c|c|}
\hline & & GFP & E & A & $\mathrm{C}$ & $\mathrm{N}$ & $\mathrm{O}$ \\
\hline 1. & I am the life of the party & .29 & .42 & & & & \\
\hline 2. & I feel little concern for others & -.60 & & -.46 & & & \\
\hline 3. & I am always prepared & .47 & & & .27 & & \\
\hline 4. & I get stressed out easily & -.43 & & & & .47 & \\
\hline 5. & I have a rich vocabulary & .46 & & & & & .29 \\
\hline 6. & I don't talk a lot & -.65 & $-.06 \mathrm{~ns}$ & & & & \\
\hline 7. & I am interested in people & .62 & & .12 & & & \\
\hline 8. & I leave my belongings around & -.53 & & & -.17 & & \\
\hline 9. & I am relaxed most of the time & .42 & & & & $.00 \mathrm{~ns}$ & \\
\hline 10. & I have difficulty understanding abstract ideas & -.49 & & & & & -.18 \\
\hline 11. & I feel comfortable around people & .58 & .39 & & & & \\
\hline 12. & I insult people & -.58 & & -.43 & & & \\
\hline 13. & I pay attention to details & .42 & & & .38 & & \\
\hline 14. & I worry about things & -.48 & & & & .37 & \\
\hline 15. & I have a vivid imagination & .41 & & & & & .44 \\
\hline 16. & I keep in the background & -.63 & $.01 \mathrm{~ns}$ & & & & \\
\hline 17. & I sympathize with others' feelings & .56 & & $.03 \mathrm{~ns}$ & & & \\
\hline 18. & I make a mess of things & -.64 & & & -.07 & & \\
\hline 19. & I seldom feel blue & .34 & & & & $-.04 \mathrm{~ns}$ & \\
\hline 20. & I am not interested in abstract ideas & -.21 & & & & & -.14 \\
\hline 21. & I start conversations & .44 & .54 & & & & \\
\hline 22. & I am not interested in other people's problems & -.60 & & -.45 & & & \\
\hline 23. & I get chores done right away & .50 & & & .41 & & \\
\hline 24. & I am easily disturbed & -.44 & & & & .51 & \\
\hline 25 . & I have excellent ideas & .43 & & & & & .40 \\
\hline 26. & I have little to say & -.68 & .06 & & & & \\
\hline 27. & I have a soft heart & .52 & & .07 & & & \\
\hline 28. & I often forget to put things back in their proper place & -.56 & & & -.16 & & \\
\hline 29. & I get upset easily & -.45 & & & & .32 & \\
\hline 30. & I do not have a good imagination & -.56 & & & & & -26 \\
\hline 31. & I talk to a lot of different people at parties & .52 & .45 & & & & \\
\hline 32. & I am not really interested in others & -.63 & & -.44 & & & \\
\hline 33. & I like order & .46 & & & .46 & & \\
\hline 34. & I change my mood a lot & -.52 & & & & .48 & \\
\hline 35. & I am quick to understand things & .45 & & & & & .29 \\
\hline 36. & I don't like to draw attention to myself & -.34 & -.15 & & & & \\
\hline 37. & I take time out for others & .57 & & $.04 \mathrm{~ns}$ & & & \\
\hline 38. & I shirk my duties & -.63 & & & -.16 & & \\
\hline 39. & I have frequent mood swings & -.57 & & & & .30 & \\
\hline 40. & I use difficult words & -.07 & & & & & .11 \\
\hline 41. & I don't mind being the centre of attention & .35 & .46 & & & & \\
\hline 42. & I feel others' emotions & .44 & & -.13 & & & \\
\hline 43. & I follow a schedule & .52 & & & .38 & & \\
\hline 44. & I get irritated easily & -.53 & & & & .35 & \\
\hline 45 . & I spend time reflecting on things & -.28 & & & & & .30 \\
\hline 46. & I am quiet around strangers & -.54 & -.14 & & & & \\
\hline 47. & I make people feel at ease & .58 & & $-.05 \mathrm{~ns}$ & & & \\
\hline 48. & I am exacting in my work & .53 & & & .25 & & \\
\hline 49. & I often feel blue & -.64 & & & & .22 & \\
\hline 50. & I am full of idea & .37 & & & & & .48 \\
\hline
\end{tabular}

$N=1669 ; \mathrm{GFP}=$ the general factor of personality $\mathrm{O}=$ openness, $\mathrm{C}=$ conscientiousness, $\mathrm{E}=$ extraversion, $\mathrm{A}=$ agreeableness, $\mathrm{N}=$ neuroticism; in case of items without precise $p$ value $p<.001, \mathrm{~ns}-$ non-significant

Open Access This article is distributed under the terms of the Creative Commons Attribution 4.0 International License (http:// creativecommons.org/licenses/by/4.0/), which permits unrestricted use, distribution, and reproduction in any medium, provided you give appropriate credit to the original author(s) and the source, provide a link to the Creative Commons license, and indicate if changes were made.

\section{References}

Acar, S., \& Runco, M. A. (2012). Psychoticism and creativity: A metaanalytic review. Psychology of Aesthetics, Creativity, and the Arts, 4, 341-350.
Akse, J., Hale, W. W., III, Engles, R. R. C. M. E., Raaijmakers, Q. A. W., \& Meeus, W. H. (2007). Co-occurrence of depression and delinquency in personality types. European Journal of Personality, 21, $235-256$.

Asendorpf, J. B., \& van Aken, M. A. (1999). Resilient, overcontrolled, and undercontroleed personality prototypes in childhood: Replicability, predictive power, and the trait-type issue. Journal of Personality and Social Psychology, 77, 815-832.

Bäckström, M., Björklund, F., \& Larsson, M. R. (2009). Five-factor inventories have a major general factor related to social desirability which can be reduced by framing items neutrally. Journal of Research in Personality, 43, 335-344.

Batey, M. (2012). The measurement of creativity: From definitional consensus to the introduction of a new heuristic framework. Creativity Research Journal, 24(1), 55-65. 
Beaussart, M. L., Andrews, C. J., \& Kaufman, J. C. (2013). Creative liars: The relationship between creativity and integrity. Thinking Skills and Creativity, 9, 129-134.

Carson, S. H., Peterson, J. B., \& Higgins, D. M. (2005). Reliability, validity, and factor structure of the creative achievement questionnaire. Creativity Research Journal, 17, 37-50.

Cropley, D. H., \& Cropley, A. J. (2010). Functional creativity: Products and the generation of effective novelty. In J. C. Kaufman \& R. J. Sternberg (Eds.), Cambridge handbook of creativity (pp. 301-318). New York: Cambridge University Press.

Cropley, D. H., \& Cropley, A. J. (2013). Creativity and crime: A psychological analysis. New York: Cambridge University Press.

Cropley, D. H., Kaufman, J. C., \& Cropley, A. J. (2008). Malevolent creativity. Creativity Research Journal, 20, 105-115.

Cropley, D. H., Cropley, A. J., Kaufman, J. C., \& Runco, M. A. (Eds.). (2010). The dark side of creativity. New York: Cambridge University Press.

Csikszentmihalyi, M., Condren, M., \& Lebuda, I. (2017). In S. T., Allison, G. R. Goethals, R. M., Kramer (Ed.), The Handbook of heroism and heroic leadership Deviant heroes and social heroism in everyday life: Activists and artists (pp. 249-261). New York: Routledge Press.

Dacey, J. S., \& Lennon, K. (1998). Understanding creativity: The interplay of biological, psychological, and social factors. San Francisco: Jossey-Bass.

De Dreu, C. K. W., \& Nijstad, B. A. (2008). Mental set and creative thought in social conflict: Threat rigidity versus motivated focus. Journal of Personality and Social Psychology, 95, 648-661.

Decuyper, M., De Pauw, S., De Fruyt, F., De Bolle, M., \& De Clercq, B. J. (2009). A meta-analysis of psychopathy, antisocial PD and FFM associations. European Journal of Personality, 23, 531-565.

Eysenck, H. J. (1993). Creativity and personality: Suggestions for a theory. Psychological Inquiry, 4, 147-178.

Eysenck, H. J. (1994). Personality: Biological foundations. In P. A. Vernon (Ed.), The neuropsychology of individual differences (pp. 151-207). San Diego, CA, US: Academic Press.

Eysenck, H. J. (1995). Genius. The natural history of creativity. Cambridge: Cambridge University Press.

Feist, G. J. (1998). A meta-analysis of personality in scientific and artistic creativity. Personality and Social Psychology Review, 2, 290-309.

Feist, G. J. (1999). The influence of personality on artistic and scientific creativity. In R. J. Sternberg (Ed.), Handbook of creativity (pp. 273296). Cambridge: Cambridge University Press.

Firkowska, A., Ostrowska, A., Sokolowska, M., Stein, Z., Susser, M., \& Wald, I. (1978). Cognitive development and social policy. Science, 200, 1357-1362.

Firkowska-Mankiewicz, A. (2002). Intelligence and success in life. Warsaw: IFiS Publishers.

Firkowska-Mankiewicz, A. (2011). Adult careers: Does childhood IQ predict later life outcome? Journal of Policy and Practice in Intellectual Disabilities, 1, 1-9.

Galang, A. J. R. (2010). The prosocial psychopath: Explaining the paradoxes of the creative personality. Neuroscience and Biobehavioral Reviews, 34, 1241-1248.

Galang, A. J. R., Castelo, V. L. C., Santos, L. C., III, Perlas, C. M. C., \& Angeles, M. A. B. (2016). Investigating the prosocial psychopath model of the creative personality: Evidence from traits and psychophysiology. Personality and Individual Differences, 100, 28-36.

Gamman, L., \& Raein, M. (2010). Reviewing the art of crime - What, if anything, do criminals and artists/designers have in common? In D. H. Cropley, A. J. Cropley, J. C. Kaufman, \& M. A. Runco (Eds.), The dark side of creativity (pp. 155-176). Cambridge: Cambridge University Press.

Gino, F., \& Ariely, D. (2012). The dark side of creativity: Original thinkers can be more dishonest. Journal of Personality and Social Psychology, 102, 445-459.
Gino, F., \& Wiltermuth, S. S. (2014). Evil genius? How dishonesty can lead to greater creativity. Psychological Science, 25, 973-981.

Goldberg, L. R. (1999). A broad-bandwidth, public domain, personality inventory measuring the lower-level facets of several five-factor models. In I. Mervielde, I. Deary, F. De Fruyt, \& F. Ostendorf (Eds.), Personality psychology in Europe (Vol. 7, pp. 7-28). Tilburg: Tilburg University Press.

Goldberg, L. R., Johnson, J. A., Eber, H. W., Hogan, R., Ashton, M. C., Cloninger, C. R., \& Gough, H. G. (2006). The international personality item pool and the future of public-domain personality measures. Journal of Research in Personality, 40, 84-96.

Götz, K. O., \& Götz, K. (1979). Personality characteristics of successful artists. Perceptual and Motor Skills, 49, 919-924.

Hall, W. B., \& MacKinnon, D. W. (1969). Personality inventory correlates of creativity among architects. Journal of Applied Psychology, $53,322-326$

Howarth, E. (1986). What does Eysenck's psychoticism scale really measure? British Journal of Psychology, 77, 223-227.

Hu, L. T., \& Bentler, P. M. (1999). Cut off criteria for fit indexes in covariance structure analysis: Conventional criteria versus new alternatives. Structural Equation Modelling, 6, 1-55.

Johnson, J. A. (1983). Criminality, creativity, and craziness: structural similarities in three types of nonconformity. In W. S. Laufer \& J. M. Day (Eds.), Personality theory, moral development, and criminal behavior (pp. 81-105). Lexington: D. C. Heath.

Jonason, P. K., Richardson, E. N., \& Potter, L. (2015). Self-reported creative ability and the dark triad traits: An exploratory study. Psychology of Aesthetics, Creativity, and the Arts, 9, 488-494.

Jonason, P. K., Abboud, R., Tomé, J., Dummett, M., \& Hazer, A. (2017). The dark triad traits and self-reported and other-rated creativity. Personality and Individual Differences, 117, 150-154.

Just, C. (2011). A review of literature on the general factor of personality. Personality and Individual Differences, 50, 765-771.

Kapoor, H., \& Khan, A. (2017). Deceptively yours: Valence-based creativity and deception. Thinking Skills and Creativity, 23, 199-206.

Karwowski, M., \& Lebuda, I. (2016). The big five, the huge two, and creative self-beliefs: A meta-analysis. Psychology of Aesthetics, Creativity, and the Arts, 10, 214-232.

Karwowski, M., Lebuda, I., Wisniewska, E., \& Gralewski, J. (2013). Big five personality traits as the predictors of creative self-efficacy and creative personal identity: Does gender matter? Journal of Creative Behavior, 47, 215-232.

Karwowski, M., Kaufman, J. C., Lebuda, I., Szumski, G., \& FirkowskaMankiewicz, A. (2017). Intelligence in childhood and creative achievements in middle-age: The necessary condition approach. Intelligence, 64, 36-44.

Kaufman, J. C., \& Beghetto, R. A. (2009). Beyond big and little: The four C model of creativity. Review of General Psychology, 13, 1-12.

Kaufman, S. B., Quilty, L. C., Grazioplene, R. G., Hirsh, J. B., Gray, J. R., Peterson, J. B., et al. (2015). Openness to experience and intellect differentially predict creative achievement in the arts and sciences. Journal of Personality, 82, 248-258.

Kenny, D. A., Kaniskan, B., \& McCoach, D. B. (2015). The performance of RMSEA in models with small degrees of freedom. Sociological Methods \& Research, 44, 486-507.

Kharkhurin, A. V. (2014). Creativity. 4in1: Four-criterion construct of creativity. Creativity Research Journal, 26, 338-352.

Kipper, D. A., Green, D. J., \& Prorak, A. (2010). The relationship among spontaneity, impulsivity, and creativity. Journal of Creativity in Mental Health, 5, 39-53.

Lee, S. A., \& Dow, G. T. (2011). Malevolent creativity: Does personality influence malicious divergent thinking? Creativity Research Journal, 23, 73-82.

Liu, C., Shen, W. B., \& Luo, J. (2014). Positive association between creativity and morality: Evidence from cognitive neuroscience. Journal of Nanjing Normal University, 194, 104-115. 
Lo, Y., Mendell, N. R., \& Rubin, D. B. (2001). Testing the number of components in a normal mixture. Biometrika, 88, 767-778.

Lynam, D., \& Miller, J. (2004). Personality pathways to impulsive behavior and their relations to deviance: Results from three samples. Journal of Quantitative Criminology, 20, 319-341.

Mai, K. M., Ellis, A. P. J., \& Welsh, D. T. (2015). The grey side of creativity: Exploring the role of activation in the link between creative personality and unethical behavior. Journal of Experimental Social Psychology, 60, 76-85.

Marshall, J., Watts, A. L., Frankel, E. L., \& Lilienfeld, S. O. (2017). An examination of psychopathy's relationship with two indices of moral judgment. Personality and Individual Differences, 113, 240-245.

Marshall, J., Watts, A. L., \& Lilienfeld, S. O. (2018). Do psychopathic individuals possess a misaligned moral compass? A meta-analytic examination of psychopathy's relations with moral judgment. Personality Disorders: Theory, Research, and Treatment, 9, 40-50.

Martindale, C. (1999). In R. J. Sternberg (Ed.), Handbook of creativity Biological bases of creativity (pp. 137-152). Cambridge: Cambridge University Press.

Matthews, G., \& Gilliland, K. (1999). The personality theories of H. J. Eysenck and J. A. Gray: A comparative review. Personality and Individual Differences, 26, 583-626.

McKay, A. S., Karwowski, M., \& Kaufman, J. C. (2017). Measuring the muses: Validating the Kaufman domains of creativity scale $(\mathrm{K}$ DOCS). Psychology of Aesthetics, Creativity, and the Arts, 11, 216-230.

Miller, J. D., \& Lynam, D. R. (2001). Structural models of personality and their relation to antisocial behavior: A meta-analysis. Criminology, 39, 765-798.

Musek, J. (2007). A general factor of personality: Evidence for the big one in the five-factor model. Journal of Research in Personality, 41, $1213-1233$

Muthén, B. O. (1993). Goodness of fit with categorical and other nonnormal variables. In K. A. Bollen \& J. S. Long (Eds.), Testing structural equation models (pp. 205-243). Newbury Park: Sage.

Muthén, L.K. and Muthén, B.O. (1998-2017). Mplus User's Guide. Eighth Edition.Los Angeles, CA: Muthén \& Muthén.

Niepel, C., Mustafić, M., Greiff, S., \& Roberts, R. D. (2015). The dark side of creativity revisited: Is students' creativity associated with subsequent decreases in their ethical decision making? Thinking Skills and Creativity, 18, 43-52.

Piff, P. K., Stancato, D. M., Cote, S., Mendoza-Denton, R., \& Keltner, D. (2012). Higher social class predicts increased unethical behavior. Proceedings of the National Academy of Science, 109, 4086-4091.

Robins, R. W., John, O. P., Caspi, A., Moffitt, T. E., \& StouthamerLoeber, M. (1996). Resilient, overcontrolled, and undercontrolled boys: Three replicable personality types. Journal of Personality and Social Psychology, 70, 157-171.

Rosseel, Y. (2012). Lavaan: An R package for structural equation modelling. Journal of Statistical Software, 48, 1-36.

Runco, M. A., \& Nemiro, J. (2003). Creativity in the moral domain: Integration and implications. Creativity Research Journal, 15, 91105.

Saggino, A. (2000). The big three or the big five? A replication study. Personality and Individual Differences, 28, 879-886.

Shen, W., Yuan, Y., Yi, B., Liu, C., \& Zhan, H. (2017). A theoretical and critical examination on the relationship between creativity and morality. Current Psychology. https://doi.org/10.1007/s12144-0179613-9.

Silvia, P. J., Kaufman, J. C., \& Pretz, J. E. (2009). Is creativity domainspecific? Latent class models of creative accomplishments and creative self-descriptions. Psychology of Aesthetics, Creativity, and the Arts, 3, 139-148.

Silvia, P. J., Kaufman, J. C., Reiter-Palmon, R., \& Wigert, B. (2011). Cantankerous creativity: Honesty-humility, agreeableness, and the HEXACO structure of creative achievement. Personality and Individual Differences, 51, 687-689.

Silvia, P. J., Wigert, B., Reiter-Palmon, R., \& Kaufman, J. C. (2012). Assessing creativity with self-report scales: A review and empirical evaluation. Psychology of Aesthetics, Creativity, and the Arts, 6, 1934.

Strus, W., Cieciuch, J., \& Rowiński, T. (2014). Polska adaptacja kwestionariusza IPIP-BFM- 50 do pomiaru pięciu cech osobowości w ujęciu leksykalnym. Roczniki Psychologiczne, 17, $327-346$

Walczyk, J. J., Runco, M. A., Tripp, S. M., \& Smith, C. E. (2008). The creativity of lying: Divergent thinking and ideational correlates of the resolution of social dilemmas. Creativity Research Journal, 20, 328-342.

Weir, R. C., \& Gjerde, P. F. (2002). Preschool personality prototypes: Internal coherence, cross-study replicability, and developmental outcomes in adolescence. Personality and Social Psychology Bulletin, $28,1229-1241$.

Zenasni, F., \& Lubart, T. I. (2009). Perception of emotion, alexithymia and creative potential. Personality and Individual Differences, 46, 353-358.

Publisher's note Springer Nature remains neutral with regard to jurisdictional claims in published maps and institutional affiliations. 